\title{
The evaluation of serum homocysteine, folic acid, and vitamin B12 in patients complicated with preeclampsia
}

\author{
Nahid Shahbazian ${ }^{1}$, Razieh Mohammad Jafari², Sahar Haghnia ${ }^{3}$
}

${ }^{1}$ M.D., Gynecologist, Full Professor, Department of Obstetrics and Gynecology, Fertility, Infertility and Perinatology Research Center, Faculty of Medicine, Ahvaz Jundishapour University of Medical Sciences, Ahvaz, Iran

${ }^{2}$ M.D., Gynecologist, Associate Professor, Department of Obstetrics and Gynecology, Fertility, Infertility and Perinatology Research Center, Faculty of Medicine, Ahvaz Jundishapour University of Medical Sciences, Ahvaz, Iran

${ }^{3}$ M.D., Resident of Obstetrics and Gynecology, Department of Obstetrics and Gynecology, Fertility, Infertility and Perinatology Research Center, Faculty of Medicine, Ahvaz Jundishapour University of Medical Sciences, Ahvaz, Iran

\section{Type of article: Original}

\begin{abstract}
Introduction: Increased plasma homocysteine may be associated with adverse pregnancy outcomes, such as preeclampsia. The aim of this study was to determine the plasma homocysteine, serum folate, and vitamin B12 levels in preeclamptic pregnant women.

Methods: This case-control study was conducted in 2016 in Ahwaz on 51 pregnant women with preeclampsia and 51 healthy pregnant women of the same gestational age, who served as controls. The case group also was subdivided into severe and non-severe preeclampsia. Patients' data were collected through a questionnaire and medical records. Serum homocysteine, folic acid, and vitamin B12 were analyzed using chemiluminescent assay. The results were compared between two groups. Statistical analyses were done using IBM-SPSS 20.0. A Kolmogorov-Smirnov test, independent samples t-test, Mann-Whitney test, and Chi-square test were used for data analysis.

Results: No different demographic characteristics were found among the groups. Pregnant women complicated with preeclampsia displayed significantly higher serum homocysteine levels $(\mathrm{p}<0.001)$ and lower serum folate $(\mathrm{p}=0.005)$ and vitamin B12 levels $(\mathrm{p}<0.001)$ compared to controls. A statistically significant inverse correlation was evident between serum homocysteine and serum folate levels in preeclamptic patients $(p=0.005 ; r=-0.389)$. In addition, an inverse correlation was identified between homocysteine and serum vitamin B12, but it was not statistically significant $(p=0.160 ; r=-0.200)$. Significant differences occurred in serum homocysteine and folate levels between the severe and non-severe subgroups $(\mathrm{p}<0.001, \mathrm{p}<0.001)$.

Conclusion: Women complicated with preeclampsia displayed higher maternal serum homocysteine and lower serum folate and vitamin B12. Further studies are needed to confirm if the prescription of folic acid and vitamin B12 in women with a deficiency of these vitamins could decrease the level of serum homocysteine and, therefore, reduce the risk of preeclampsia or, if it occurred, its severity.

Keywords: Homocysteine, Folic acid, Vitamin B12, Preeclampsia
\end{abstract}

\section{Introduction}

\subsection{Background}

Hypertensive disorders of pregnancy are considered as an important cause of severe morbidity and mortality among mothers and infants (1). Preeclampsia can be a hypertensive disorder complicating $5 \%-8 \%$ of all pregnancies (2).

\section{Corresponding author:}

Dr. Sahar Haghnia, Department of Gynecology, Faculty of medicine, Jundishapour University of Medical Sciences. Tel: +98.9173611726, Email: sahar.haghnia@gmail.com

Received: May 01, 2016, Accepted: June 04, 2016, Published: October 2016

iThenticate screening: June 04, 2016, English editing: July 27, 2016, Quality control: September 01, 2016

(C) 2016 The Authors. This is an open access article under the terms of the Creative Commons Attribution-NonCommercialNoDerivs License, which permits use and distribution in any medium, provided the original work is properly cited, the use is non-commercial and no modifications or adaptations are made. 
According to a systemic review and meta-analysis published in 2013, preeclampsia has a noticeable relationship with an increased risk of developing hypertension, ischemic heart disease, and cerebrovascular accident in later life (3). Furthermore, it is associated with fetal growth restriction, low birth weight, preterm birth, respiratory distress syndrome, and admission to a neonatal intensive care unit (4).

\subsection{Statement of problem}

Homocysteine is an amino acid containing sulfur, which plays important roles in humans' metabolic pathways. These roles include cystathionine formation and methionine reformation. It needs methyl groups for its action, which takes it away from the folic acid pathway. Methionine synthase plays a catalyzer role in this reaction, which requires the presence of vitamin B12. A reduction in plasma concentrations of vitamin B12 or folic acid increases the homocysteine levels (5). Hyperhomocysteinemia is associated with preeclampsia (6-9), increased risk of SGA (10), pregnancy loss (9), and premature delivery (11). High levels of homocysteine are associated with higher risks of cardiovascular diseases (12). The mechanism is poorly understood, but high homocysteine levels seem to alter endothelial nitric oxide secretions, thereby inducing hypertension and ischemia (13). During a normal pregnancy, plasma homocysteine concentrations will decrease (5). High levels of maternal serum homocysteine are associated with higher rates of pregnancy complications, but the evidence is conflicting (14). Previous studies have shown higher levels of homocysteine in preeclamptic women; they are detected in early pregnancy and remain elevated until delivery (15). Low maternal folate concentrations are associated with preeclampsia $(9,10,16)$. The ability to screen women at risk for preeclampsia would increase the potential for strategies of prevention (8).

\subsection{Objectives}

The aim of this study was to determine whether serum homocysteine is higher in pregnant women complicated with preeclampsia compared to normal pregnant controls as well as to investigate whether it could be related to folate or vitamin B12 deficiency. In addition, it examines whether different levels of homocysteine are associated with the severity of the disease.

\section{Material and Methods}

\subsection{Study design}

This case-control study was conducted within hospitals associated with academic medical centers of Ahwaz, Iran, from January to April 2016.

\subsection{Sampling}

The study included a sample of preeclamptic pregnant women with gestational age 34 weeks and more $(\mathrm{N}=51)$ aged 18-40 years, and 51 normal healthy pregnant women at the same gestational age as controls. The sample size was determined for the power and confidence of $90 \%$. Women with a history of chronic hypertension, overt or gestational diabetes mellitus, kidney disease, hemoglubinopathies, megaloblastic anemia, seizure, prior significant illness, personal or familial history of deep vein thrombosis, and/or vitamin deficiency as well as those receiving any anti-folate drugs (antiepileptics, methotrexate) were excluded. In addition, in the presence of intrauterine growth restriction or new onset of grand mal seizure, considered to have ecclampsia, the patients were excluded. The subjects were not in active labor.

\subsection{Measurement tools}

Participants were informed of the study, and written informed consents were received from all participants in this study. Data obtained from face-to-face interviews and medical records were recorded in a specific questionnaire designed for this study.

\subsection{Data collection}

Preeclampsia was defined as having blood pressure $\geq 140 / 90 \mathrm{mmHg}$ on at least two occasions, 6 hours apart, associated with proteinuria, which was defined as urine protein concentrations $\geq 300 \mathrm{mg} / \mathrm{dl}$ in a 24-hour urine collection or persistent $1+$ dipstick proteins in random urine samples. Preeclamptic patients were divided to two subgroups: severe and non-severe. Severity was defined by the presence of at least one of the following criteria: blood pressure $\geq 160 / 110 \mathrm{mmHg}$ on two occasions 6 hours apart, serum creatinine $>1 \mathrm{mg} / \mathrm{dl}$, platelet count $<100000 / \mu \mathrm{L}$, aspartate aminotransferase (AST) elevated two times above upper limit of normal range, persistent headache or scotoma, persistent midepigastric or right upper quadrant pain, and/or oliguria (less than $500 \mathrm{ml}$ of urine in 24 hours). Venous blood samples were collected in test tubes containing clot activator, immediately stored on ice, 
and - one hour after collection - centrifuged at $4000 \mathrm{rpm}$ for 10 minutes. Plasma were separated and stored at $-80^{\circ} \mathrm{C}$ through the hour to be analyzed.

\subsection{Biochemical analysis}

The plasma homocysteine level was measured via the chemiluminescent method using kits from Abbott Corporation, USA. The folic acid and vitamin B12 levels were measured with electrochemiluminescence using kits from Roche Company, Germany.

\subsection{Statistical analysis}

Statistical analyses were conducted using software SPSS 20.0. A Kolmogorov-Smirnov test was used to determine whether sample data are normally distributed. We used an independent sample t-test for age, gestational age, folate, and vitamin B12, and a Mann-Whitney test for other variables. To determine the relationship between two groups in terms of folic acid consumption, we used a Fisher test and Chi-square test for the consumption of multivitamins. Correlation analyses were performed using the Pearson product-moment correlation coefficient.

\subsection{Research ethics}

This study was confirmed by the Committee of Research Ethics (code: IR.AJUMS.Rec.1394.577).

\section{Results}

Patient demographic data are shown in Table 1. The maternal demographics and gestational ages were similar between the groups (group 1: preeclamptic, group 2: normal). The consumption of folic acid depended on period of time taking medication, divided to four subgroups: I. No consumption; II. Consumption only in the first trimester; III. Consumption before pregnancy until the end of the first trimester; and IV. Consumption throughout the pregnancy period. No difference between the groups occurred in this division. In addition, there was no difference between the two groups in terms of the consumption of multivitamins. The mean homocysteine level was $8.50 \pm$ 2.19 in group 1 and $4.62 \pm 2.52$ in group 2. A significant difference emerged between the two groups $(\mathrm{p}<0.001)$. The mean serum folate was $12.3 \pm 3.62$ in group 1 and $14.24 \pm 3.89$ in group 2; a significant difference was evident between the two groups $(p=0.005)$. The mean vitamin $B 12$ was $143.32 \pm 58.88$ in group 1 and $199.71 \pm 87.36$ in group 2; a significant difference was evident between the two groups $(\mathrm{p}<0.001)$ (Table 2$)$. In group 1, a statistically significant inverse correlation occurred between serum homocysteine and serum folate $(p=0.005)$; an inverse correlation between serum homocysteine and vitamin B12 was also evident, but it was not statistically significant ( $p$ $=0.160$ ) (Table 3). Group 1 was also divided into 1a (severe) and $1 \mathrm{~b}$ (non-severe) subgroups, with significant differences in serum homocysteine and serum folate between these two subgroups. Other parameters had no significant difference (Table 4).

Table 1. Demographic data in preeclamptic patients and controls

\begin{tabular}{|l|l|l|l|}
\hline Parameters & Preeclampsia group $(\mathrm{n}=51)$ & Controls $(\mathrm{n}=51)$ & $\mathrm{p}$-value \\
\hline Age (year) & $25.76 \pm 4.52$ & $27.14 \pm 5.48$ & 0.171 \\
\hline Gestational age (week) & $36.03 \pm 1.04$ & $36.16 \pm 1.28$ & 0.577 \\
\hline Gravida & $1.61 \pm 0.78$ & $1.78 \pm 1.17$ & 0.893 \\
\hline Systolic blood pressure $(\mathrm{mmHg})$ & $149.02 \pm 10.20$ & $112.45 \pm 6.19$ & $<0.001$ \\
\hline Diastolic blood pressure $(\mathrm{mmHg})$ & $96.86 \pm 7.35$ & $65.29 \pm 5.33$ & $<0.001$ \\
\hline
\end{tabular}

Table 2. Serum total homocysteine, folic acid, and vitamin B12 in preeclamptic patients and controls

\begin{tabular}{|l|l|l|l|}
\hline Biochemical Parameters & Preeclampsia $(\mathrm{n}=51)$ & Control group $(\mathrm{n}=51)$ & $\mathrm{p}$-value \\
\hline Homocysteine $(\mu \mathrm{mol} / \mathrm{L})$ & $8.50 \pm 2.19$ & $4.62 \pm 2.52$ & $<0.001$ \\
\hline Folate $(\mathrm{ng} / \mathrm{mL})$ & $12.13 \pm 3.62$ & $14.24 \pm 3.89$ & 0.005 \\
\hline Vitamin B12 $(\mathrm{pg} / \mathrm{mL})$ & $143.32 \pm 58.88$ & $199.71 \pm 87.36$ & $<0.001$ \\
\hline
\end{tabular}

Table 3. Correlation of total homocysteine, folic acid, and vitamin B12 in preeclamptic patients

\begin{tabular}{|l|l|l|}
\hline Parameters & $\mathrm{r}$ value & $\mathrm{p}$-value \\
\hline Folic acid & -0.389 & 0.005 \\
\hline Vitamin B12 & -0.200 & 0.180 \\
\hline
\end{tabular}


http://www.ephysician.ir

Table 4. Demographic characteristics and analytes levels among severe and non-severe preeclamptic patients

\begin{tabular}{|l|l|l|l|}
\hline Parameters & Severe $(\mathrm{n}=13)$ & Non-severe $(\mathrm{n}=38)$ & $\mathrm{p}$-value \\
\hline Age $($ year $)$ & $25.38 \pm 4.13$ & $25.89 \pm 4.69$ & 0.729 \\
\hline Gestational age $($ week $)$ & $35.64 \pm 1.9$ & $36.16 \pm 1.01$ & 0.121 \\
\hline Gravida & $1.38 \pm 0.87$ & $1.68 \pm 0.74$ & 0.076 \\
\hline Systolic blood pressure $(\mathrm{mmHg})$ & $164.61 \pm 5.19$ & $143.68 \pm 4.14$ & $<0.001$ \\
\hline Diastolic blood pressure $(\mathrm{mmHg})$ & $107.31 \pm 4.38$ & $93.29 \pm 39$ & $<0.001$ \\
\hline Homocysteine $(\mu \mathrm{mol} / \mathrm{L})$ & $10.67 \pm 1.49$ & $7.76 \pm 1.88$ & $<0.001$ \\
\hline Folate $(\mathrm{ng} / \mathrm{mL})$ & $10.06 \pm 2.59$ & $12.83 \pm 3.68$ & 0.006 \\
\hline Vitamin B12 $(\mathrm{pg} / \mathrm{mL})$ & $130.01 \pm 61.32$ & $147.87 \pm 58.15$ & 0.350 \\
\hline
\end{tabular}

\section{Discussion}

The results of this study show that serum levels of homocysteine, folic acid, and vitamin B12 are altered during preeclampsia compared to pregnant women with normal blood pressure. Significant elevated levels of homocysteine and decreased serum folate and vitamin B12 were found in women with preeclampsia. High concentrations of homocysteine are a proven risk factor for vascular disease (17). It seems that high levels of homocysteine can damage endothelial cells and cause endothelial dysfunction, which is characteristic of preeclampsia. Dodds et al. showed that high homocysteine in early pregnancy is a risk factor for preeclampsia (8). In addition, elevated levels of homocysteine in women with preeclampsia exist from early pregnancy and remain high until delivery (15). Several studies have shown high concentrations of maternal serum homocysteine in preeclampsia $(6,7,9,18-20)$. The results from this study support these outcomes. Homocysteine metabolizes in two pathways. One is remethilation to methionine (7). It needs folate as a substrate and vitamin B12 as a coenzyme. The absence or lack of any of these will lead to homocysteine accumulation (16). In several studies, the reverse correlation between levels of serum folate and homocysteine has been demonstrated $(9,10,16,20)$. Furthermore, an inverse correlation exists between levels of vitamin B12 and homocysteine $(9,20)$. In this study, a significant inverse correlation was found between homocysteine and serum folate. In addition, a negative non-significant correlation occurred between levels of vitamin B12 and homocysteine, although several studies found no significant difference in serum folate and vitamin B12 between preeclampsia and control group. Also, no correlation was found between serum folate and vitamin B12 with a concentration of serum homocysteine $(6,7,19)$. The folic acid requirement during pregnancy is higher due to increased cell proliferation (9). Maternal folate levels can be determined by measuring folate's concentration in maternal serum. Folate and vitamin B12 deficiencies are associated with increased serum homocysteine, resulting in adverse pregnancy outcomes (20). This study found lower folate levels in pregnant women with preeclampsia, supporting the view that low serum folate levels in pregnancy-perhaps more obvious in women with a low socio-economic status - can lead to pregnancy complications. According to the results, by measuring the levels of serum homocysteine, folic acid, and vitamin B12, women at risk for preeclampsia could be screened. This is more important for women with risk factors or a previous history of preeclampsia.

\section{Conclusions}

Women with preeclampsia displayed higher maternal serum homocysteine and lower serum folate and vitamin B12 levels. Further studies are needed to confirm if the prescription of folic acid and vitamin B12 in women deficient in these vitamins could decrease the level of serum homocysteine, thereby reducing the risk of preeclampsia or(if it occurs) its severity.

\section{Acknowledgments:}

The paper is extracted from the results of a thesis by Sahar Haghnia for fulfillment of the requirements for a degree of specialty in obstetrics and gynecology. The study was conducted in Ahwaz University of Medical Sciences. The authors want to thank university directors and personnel for their help and support.

\section{Conflict of Interest:}

There is no conflict of interest to be declared.

Authors' contributions:

All authors contributed to this project and article equally. All authors read and approved the final manuscript. 


\section{References:}

1) Salam RA, Das JK, Ali A, Bhaumik S, Lassi ZS. Diagnosis and management of preeclampsia in community setting in low and middle-income countries. J Family Med Prim Care. 2015; 4(4): 501-6. doi: 10.4103/2249-4863.174265. PMID: 26985406, PMCID: PMC4776599.

2) Shenoy V, Kanasaki K, Kalluri R. Pre-eclampsia: connecting angiogenic and metabolic pathways. Trends Endocrinol Metab. 2010; 21(9): 529-36. doi: 10.1016/j.tem.2010.05.002. PMID: 20646932.

3) Brown MC, Best KE, Pearce MS, Waugh J, Robson SC, Bell R. Cardiovascular disease risk in women with pre-eclampsia: systematic review and meta-analysis. Eur J Epidemiol. 2013; 28(1): 1-19. doi: 10.1007/s10654-013-9762-6. PMID: 23397514.

4) Altman D, Carroli G, Duley L, Farrell B, Moodley J, Neilson J, et al. Do women with pre-eclampsia, and their babies, benefit from magnesium sulphate? The magpie Trial: A randomized placebo-controlled trial. Lancet. 2002; 359(9321): 1877-90. doi: 10.1016/S0140-6736(02)08778-0. PMID: 12057549.

5) Hague WM. Homocysteine and pregnancy. Best Pract Res Clin Obstet Gynaecol. 2003; 17(3): 459-69. doi: 10.1053/S1521-6934)03)00009-91. PMID: 12787538.

6) Makedos G, Papanicolaou A, Hitoglou A, Kalogiannidis I, Makedos A, Vrazioti V, et al. homocysteine, Folic acid and B12 serum levels in pregnancy complicated with preeclampsia. Arch Gynecol Obstet. 2007; 275(2): 121-4. doi: 10.1007/s00404-006-0223-2. PMID: 16941105.

7) Acilmis YG, Dikensoy E, Kutlar AI, Balat O, Cebesoy FB, Ozturk E, et al. homocysteine, folic acid and vitamin B12 levels in maternal and umbilical cord plasma and homocysteine levels in placenta in pregnant women with pre-eclampsia. J Obstet Gynaecol Res. 2011; 37(1): 45-50. doi: 10.1111/j.14470756.2010.01317.x. PMID: 21040211.

8) Dodds L, Fell DB, Dooley KC, Armson BA, Allen AC, Nassar BA, et al. Effect of homocysteine concentration in early pregnancy on gestational hypertensive disorders and other pregnancy outcomes. Clin Chem. 2008; 54(2): 326-34. doi: 10.1373/clinchem.2007.097469. PMID: 18070815.

9) Yanez P, Vasquez CJ, Rodas L, Duran A, Chedraui P, Liem KH, et al. Erythrocyte folate content and serum folic acid and homocysteine levels in preeclamptic primigravidae teenagers living at high altitude. Arch Gynecol Obstet. 2013; 288(5): 1011-15. doi: 10.1007/s00404-013-2851-7. PMID: 23609037.

10) Bergen NE, Jaddoe VW, Timmermans S, Hofman A, Lindemans J, Russcher H, et al. Homocysteine and folate concentrations in early pregnancy and the risk of adverse pregnancy outcomes: the generation $\mathrm{R}$ study. BJOG. 2012; 119(6): 739-51. doi: 10.1111/j.1471-0528.2012.03321.x. PMID: 22489763.

11) El-Khairy L, Vollset SE, Refsum H, Ueland PM. Plasma total cysteine, pregnancy complications, and adverse pregnancy outcomes: the Hordaland homocysteine study. Am J Clin Nutr. 2003; 77(2): 467-72. PMID: 12540409 .

12) Fenech M, Atiken C, Rinaldi J. Folate, vitamin B12, homocysteine status and DNA damage in young Australian adults. Carcinogenesis. 1998; 19(7): 1163-71. doi: 10.1093/carcin/19.7.1163. PMID: 9683174.

13) Var A, Yildirim Y, onur E, Kuscu NK, uyanik BS, Goktalay K, et al. Endothelial dysfunction in preeclampsia. Increased homocysteine and decreased nitric oxide levels. Gynecol Obstet Invest. 2003; 56(4): 221-4. doi: 10.1159/000074824. PMID: 14614253.

14) Murphy MM, Fernandez-Ballart JD. Homocysteine in pregnancy. Adv Clin Chem. 2011; 53: 105-37. doi: 10.1016/B978-0-12-385855-9.00005-9. PMID: 21404916.

15) Wadhwani NS, Patil VV, Mehendale SS, Wagh GN, Gupte SA, Joshi SR. Increased homocysteine levels exist in women with preeclampsia from early pregnancy. J Matern Fetal Neonatal Med. 2016; 29(16): 2719-25. doi: 10.3109/14767058.2015.1102880. PMID: 26552939.

16) Megahed MA, Taher IM. Folate homocysteine levels in pregnancy. Br J Biomed Sci. 2004; 61(2): 84-7. PMID: 15250671.

17) Mignini LE, Latthe PM, Villar J, Kilby MD, Carroli G, Khan KS. Mapping the theories of preeclampsia: the role of homocysteine. Obstet Gynecol. 2005; 105(2): 411-25. doi: 10.1097/01.AOG.0000151117.52952.b6. PMID: 15684173.

18) Rajkovic A, Mohamed K, Malinow MR, Sorenson TK, Woelk GB, Williams MA. Plasma homocysteine concentration in eclamptic and preeclamptic African women postpartum. Obstet Gynecol. 1999; 94(3): 355-60. doi: 10.1097/00006250-199909000-00007. PMID: 10472859.

19) Sanlikan F, Tufan F, Gocmen A, Kabadayi C, Sengul E. The evaluation of homocysteine level in patients with preeclampsia. Ginekol pol. 2015; 86(4): 287-91. doi: 10.17772/gp/2075. PMID: 26117988.

20) Mujawar SA, Patil VW, Daver RG. Study of serum homocysteine, folic acid and vitamin B12 in patients with preeclampsia. Ind J Clin Biochem. 2011; 26(3): 257-60. doi: 10.1007/s12291-011-0109-3. PMID: 22754189, PMCID: 3162959. 